Endocrine Research

\title{
Genetics of Hypospadias: Are Single-Nucleotide Polymorphisms in SRD5A2, ESR1, ESR2, and ATF3 Really Associated with the Malformation?
}

\author{
Loes F. M. van der Zanden, Iris A. L. M. van Rooij, Wout F. J. Feitz, \\ Sita H. H. M. Vermeulen, Lambertus A. L. M. Kiemeney, Nine V. A. M. Knoers, \\ Nel Roeleveld, and Barbara Franke \\ Departments of Epidemiology, Biostatistics, and Health Technology Assessment (L.F.M.v.d.Z., I.A.L.M.v.R., \\ S.H.H.M.V., L.A.L.M.K., N.R.), Urology (W.F.J.F., L.A.L.M.K.), and Human Genetics (L.F.M.v.d.Z., S.H.H.M.V., \\ N.V.A.M.K., B.F.), Radboud University Nijmegen Medical Centre, 6500 HB Nijmegen, The Netherlands
}

Context: Hypospadias is a common congenital malformation of the male external genitalia with a multifactorial etiology. Little is known about the genes involved in hypospadias. A few genetic associations have been reported but mainly in studies of small sample size. Most of these associations have not been replicated.

Objective: The aim of this study was to investigate whether previously reported associations for four single-nucleotide polymorphisms (SNPs) in genes involved in hormonal pathways could be replicated in a large Dutch hypospadias sample. The SNPs investigated are rs523349 in steroid-5 $\alpha$ reductase (SRD5A2), rs6932902 in estrogen receptor 1 (ESR1), rs2987983 in ESR2, and rs11119982 in activating transcription factor 3 (ATF3).

Design, Participants, and Methods: We genotyped 620 Caucasian hypospadias cases and 596 controls for these SNPs using TaqMan-based genotyping.

Results: We did not replicate the associations of the SNPs in SRD5A2 and ESR1 with hypospadias. The SNPs in ESR2 and ATF3 were borderline associated with hypospadias [odds ratios 0.9 (95\% confidence interval $0.7-1.0)$ and 1.2 (95\% confidence interval 1.0-1.4), respectively] but in the opposite direction compared with earlier publications. Stratification according to localization of the urethral opening produced comparable results in the subgroups.

Conclusions: The lack of consistency between our and previously performed studies might represent spurious results or chance findings in our or the earlier studies, differences in criteria used to select the study populations, or a real difference between populations, i.e. different genes contributing to disease risk. These results once again confirm the importance of replication in genetic association approaches. (J Clin Endocrinol Metab 95: 2384-2390, 2010)

$\mathbf{H}^{\mathrm{n}}$ ypospadias, a hypoplasia of the penis with proximal displacement of the urethral meatus on the ventral aspect of the penis, results from developmental arrest of the urethral fusion. The appearance of hypospadias is diverse, with the opening being located glanular, penile, scrotal, or even in the perineal region in different individuals. Although hypospadias is a common congenital dis-

ISSN Print 0021-972X ISSN Online 1945-7197

Printed in U.S.A.

Copyright (C) 2010 by The Endocrine Society

doi: 10.1210/jc.2009-2101 Received October 1, 2009. Accepted February 9, 2010.

First Published Online March 9, 2010 order affecting approximately 21 in 10000 live births in The Netherlands in 2006 (1), its etiology is incompletely understood. The development of the male external genitalia is a complex process influenced by multiple genes (2), of which those coding for sex hormones have been the focus of interest in most previous studies. Originally studies trying to elucidate the etiology of hypospadias mainly

Abbreviation: $\mathrm{Cl}$, Confidence interval; OR, odds ratio; SNP, single-nucleotide polymorphism. 
focused on male hormones, but more recently focus has broadened to include female hormones as well. Estrogen receptors are expressed in the human fetal male external genitalia (3), and exposure to estrogens seems to increase the risk of hypospadias $(4,5)$. Furthermore, estrogen-responsive genes are up-regulated in hypospadias $(6,7)$.

Hypospadias clusters within families; $7 \%$ of hypospadias cases have a first-, second-, or third-degree relative with hypospadias, whereas the expected rate of familial cases among the general population is $3 \%(8)$. This familial aggregation is believed to be caused by genetic rather than intrauterine environmental factors (9). Rare mutations in genes have been found in only a few hypospadias patients, for example in the genes encoding the androgen receptor $(A R)(10-13)$, steroid$5 \alpha$-reductase (SRD5A2) (14), hydroxy- $\delta$-5-steroid dehydrogenase (HSD3B2) (15), mastermind-like domain containing 1 [MALMD1, previously named chromosome $\mathrm{X}$ open reading frame 6 (CXorf6)] (16), and bone morphogenetic proteins 4 and 7 (BMP4 and BMP7) (17) as well as in the genes coding for homeobox A4 and B6 (HOXA4 and HOXB6) (17). However, most investigators are convinced that single mutations are not likely to be the cause of the majority of nonsyndromal hypospadias cases $(10-13,15,18)$. Segregation analysis suggests that the majority of cases have a multifactorial etiology (19).

According to the common gene, common disorder hypothesis (20), multiple frequently occurring genetic variants (polymorphisms), each with a relatively small effect, contribute to multifactorial disorders. Although not many studies investigated polymorphisms in relation to hypospadias, some associations with hypospadias have been reported, mainly of polymorphisms in endocrine-related genes, namely in $A R(21,22), \operatorname{SRD} 5 A 2(23,24)$, the genes encoding estrogen receptors 1 (ESR1) $(25,26)$ and 2 (ESR2) (26-28), and activating transcription factor 3 (ATF3) (29). Furthermore, polymorphisms in the genes encoding fibroblast growth factor 8 (FGF8) (18) and FGF receptor 2 (FGFR2) (18) have been associated with hypospadias. Overall, however, the numbers of samples analyzed in these studies were relatively small, with only 43380 cases plus controls included. Only three of the above associations (rs523349 in SRD5A2, the GGN repeat in $A R$, and the CA repeat in ESR2) have been reported in more than one study. Replication of results is a major issue in research into genetic causes of multifactorial disorders because first studies often appear to overestimate the effect of the genetic variant (so-called winner's curse) (30), and studies reporting positive results are more likely to be published than those reporting negative results (publication bias) (31). Therefore, the aim of this study was to investigate whether the previously reported associations of single-nucleotide polymorphisms (SNPs) in genes involved in hormonal pathways could be replicated in a large Dutch sample of 620 hypospadias cases and 596 controls.

SNPs in four genes were studied; SRD5A2, ESR1, ESR2, and ATF3. SRD5A2 encodes an enzyme that converts circulating testosterone in the genital tubercle to the more potent androgen dihydrotestosterone, which stimulates normal differentiation and development of the genital tubercle into the external genitalia (2). ESR1 and ESR2 encode estrogen receptors, and ATF3 is an estrogenresponsive gene, showing strong up-regulation in hypospadias $(6,7)$. Furthermore, we investigated whether localization of the meatus influenced our findings because hypospadias with different localizations of the urethral opening arise at distinct embryologic stages with different genes likely to be involved in the process.

\section{Subjects and Methods}

\section{Cases and controls}

The Aetiologic Research into Genetic and Occupational/Environmental Risk Factors for Anomalies in Children (AGORA) project of the Radboud University Nijmegen Medical Centre aims at building a data bank and biobank with questionnaire data and DNA samples from patients with a congenital disorder and their parents. For the current study, DNA collected prospectively and retrospectively was available from 679 hypospadias cases. The majority of the cases were of European Caucasian descent $(92 \%)$, whereas descent was not Caucasian $(5 \%)$ or unknown (3\%) for the remaining cases. Only Caucasian cases were included in the analyses. The retrospectively collected cases $(\mathrm{n}=$ 478) have been described before in studies on environmental risk factors for hypospadias $(32,33)$. Routine data collection since 2005 provided the prospective cases. Medical records of all cases were reviewed to identify syndromal cases of hypospadias and clinical characteristics of patients and determine the anatomical location of the urethral opening. The location was determined by experienced pediatric urologists during physical examination before surgery. For the current study, anatomical location was subdivided into three categories: anterior hypospadias (glanular and subcoronal), middle hypospadias (penile), and posterior hypospadias (penoscrotal, scrotal, and perineal).

Controls were obtained from the Nijmegen Biomedical Study, a population-based survey conducted by the Department of Epidemiology, Biostatistics, and Health Technology Assessment and the Department of Clinical Chemistry of the Radboud University Nijmegen Medical Centre in 2003. Age- and sexstratified randomly selected inhabitants of the municipality of Nijmegen $(\mathrm{n}=22500)$ received an invitation to fill out a postal questionnaire, e.g. on lifestyle and medical history, and to donate blood samples. The response to the questionnaire was $42 \%(n=9373)$, whereas $72 \%(n=6747)$ of the responders also donated blood samples (34). The 596 youngest males of Dutch descent were selected for the current study. None of them had reported penile surgery in the self-report questionnaires administered by the Nijmegen Biomedical Study.

The regional Committee on Research Involving Human Subjects approved both studies. All participants gave written informed consent for participation in the study. 


\section{Genotyping}

Blood was collected in EDTA containing tubes for the largest part of the study population $(\mathrm{n}=980)$, whereas saliva was collected using Oragene containers ( $\mathrm{n}=295$; DNA Genotek Inc., Ottawa, Ontario, Canada). DNA was extracted from blood or saliva using standard methods. Samples were genotyped for rs523349 in SRD5A2 (23, 24), rs6932902 in ESR1 (25), rs2987983 in ESR2 (27), and rs11119982 in ATF3 (29) using 5 '-nuclease TaqMan SNP genotyping assays (SRD5A2: C_2362601_10, ESR1: C_2823640_10, ESR2: C_1436929_20, ATF3: C_27262262_10; Applied Biosystems, Foster City, CA). PCRs were carried out in 96-well plates in a $10-\mu$ l volume containing 10 ng genomic DNA, $5 \mu$ l Taqman universal PCR master mix, $0.125 \mu$ lassay mix, and milli-Q. The PCR consisted of an initial denaturation step at $95 \mathrm{C}$ for $10 \mathrm{~min}$ followed by 40 cycles of denaturation at $92 \mathrm{C}$ for $15 \mathrm{sec}$ and annealing and extension at $60 \mathrm{C}$ for $60 \mathrm{sec}$. After PCR, allele-specific fluorescence was measured on an ABI 7500 FAST (Applied Biosystems). In each plate, five wells were loaded with randomly selected duplicate DNA samples from the same and other plates for quality control purposes. In addition, four blanks were included in each plate. Genotyping was carried out in a laboratory recognized and granted accreditation for quality control by the coordinating committee for improvement of quality control of laboratory research in health care.

\section{Statistical analysis}

Statistical analyses were performed using SPSS 16.0 (SPSS, Chicago, IL). Genotype frequencies in controls were tested for accordance with Hardy-Weinberg equilibrium. For the four SNPs, the most frequent homozygous genotypes in controls were used as reference values. Odds ratios (OR) for hypospadias risk and corresponding $95 \%$ confidence intervals (CI) were calculated at genotype and allelic level. Furthermore, $\chi^{2}$ tests were performed. $P<0.05$ was considered statistically significant in the primary analyses. Applying the Bonferroni correction for multiple comparisons decreased the significance threshold to 0.004 for the 12 comparisons made.

In a second step, cases were subdivided into anterior, middle, and posterior categories, and the statistical analyses were repeated. Furthermore, to exclude bias due to the different sources of DNA (i.e. blood and saliva), the analyses were repeated separately for cases of whom DNA was obtained from either blood or saliva.

To enable a better comparison between the results of our study and the previously published results, we recalculated the risk estimates of these studies according to the procedures described above. Exact $95 \% \mathrm{CI}$ around the ORs were calculated using the Fisher exact method, whenever expected cell numbers were below five.

\section{Results}

Figure 1 shows a flow chart of the collection and selection of cases for this study. In the analysis of the complete sample, 620 cases were included, whereas in the second step of the analysis, 579 case samples could be included for whom the hypospadias location had been determined. Table 1 shows the clinical characteristics of the patients. More than half of the posterior cases underwent the onlay

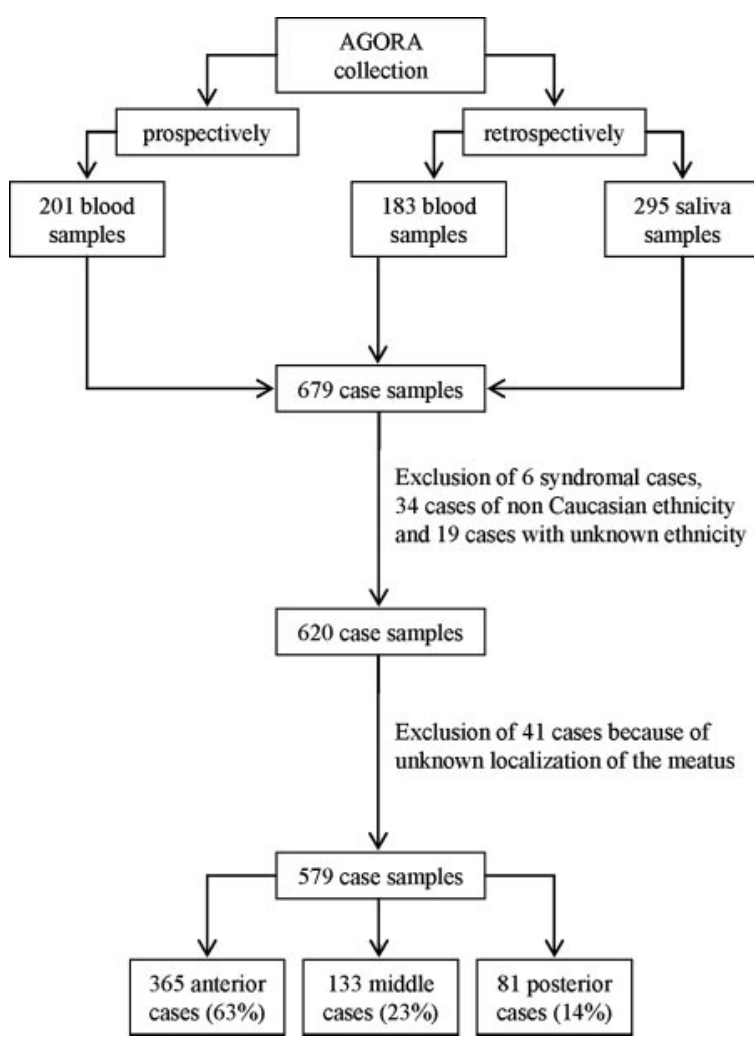

FIG. 1. Flow chart of the selection of case samples for inclusion in the current study. AGORA, Aetiologic Research into Genetic and Occupational/Environmental Risk Factors for Anomalies in Children.

island flap procedure. Other techniques used were the tubular graft (Duckett's procedure) and tubularized incised plate urethroplasty. One third of these posterior hypospadias cases needed a two-stage repair.

Genotyping of the four SNPs was completed with a success rate of more than $99 \%$. All genotype frequencies in controls were in Hardy Weinberg equilibrium (SRD5A2: $P=$ 0.63; ESR1: $P=0.98$; ESR2: $P=0.22$; ATF3: $P=0.31$ ).

Table 2 presents the results of the primary genotype and allele association analyses of the four SNPs. For the SNP in SRD 5A2, there was no indication of an association with hypospadias in our sample, neither at the genotypic nor at the allelic level. For the SNPs in ESR1 and ATF3, odds ratio for the risk of hypospadias were statistically significantly increased for both variant genotypes (ATF3) and the variant allele (ESR1, ATF3). For the SNP in ESR2, both variant genotypes and the variant allele appeared to be negatively associated with hypospadias, although not statistically significant. After correction for multiple testing, none of the results remained statistically significant. Separate analyses for the anterior, middle, and posterior categories of hypospadias and for DNA obtained from blood and saliva showed comparable results in the subgroups (data not shown).

In Table 3 our results are compared with the results of previously reported studies. We were unable to replicate the results of Wang et al. and Thai et al. reporting an 
association of rs523349 in SRD5A2 with hypospadias in 90 Chinese cases and 87 controls (24) and 158 Swedish, Turkish, and Middle Eastern cases and 96 Swedish controls (23), respectively. We did not replicate the association of rs6932902 in ESR1 with hypospadias either, as reported earlier by Watanabe et al. (25) in 43 Japanese cases and 135 controls. These authors investigated eight SNPs covering a linkage disequilibrium block in ESR 1 and found the strongest association with hypospadias for rs6932902, which was nonsignificant in our sample, although showing a trend in the same direction. Our findings for rs2987983 in ESR2 and rs11119982 in ATF3 showed trends in the opposite direction compared with the earlier publications by Beleza-Meireles et al. (27), who genotyped four haplotype-tagging SNPs in ESR2 in a Swedish cohort of 348 cases and 377 controls and reported a statistically significant association with hypospadias for rs2987983. They also genotyped 330 cases and 374 controls for eight haplotype-tagging SNPs in ATF3 and concluded that rs11119982 was negatively associated with hypospadias (29), whereas a positive association was observed in our study.

\section{Discussion}

It is a well-known fact that most associations reported in genetic studies do not replicate across subsequent studies (35). This is true even for studies investigating very plausible candidate genes for a phenotype or disorder, as is the case in the current study, in which, among others, a gene implicated in monogenic forms of hypospadias (SRD5A2) was investigated. To our knowledge, the current study investigated the largest sample of hypospadias cases and controls for associated SNPs thus far reported. We were unable to replicate the results of three earlier studies in Caucasian populations. As for the results of the two earlier studies in non-Caucasian populations, these findings did not generalize to our Caucasian population. The lack of consistency between our study and previously performed studies might be caused by spurious results or chance findings found in our or the earlier studies, especially in those with very small sample sizes, differences in the criteria used to select cases and/or controls, or a real difference between the populations (36).

Population stratification, which occurs when cases and controls are drawn from different subgroups that differ in disease prevalence and frequency of the genetic variant, may lead to spurious results. We selected only Caucasian cases and controls living in the same area in The Netherlands to minimize the chance of population stratification. Thai et al. (23) included cases from Sweden, Turkey, and the Middle East, whereas all controls were Swedish, but 
TABLE 2. Association analyses for single nucleotide polymorphisms in SRD5A2, ESR1, ESR2 and ATF3 with hypospadias

\begin{tabular}{|c|c|c|c|c|c|c|c|c|c|c|}
\hline & $\begin{array}{l}\text { Controls } \\
\mathrm{n}=596(\%)\end{array}$ & $\begin{array}{l}\text { Cases } \\
n=620(\%)\end{array}$ & OR & $(95 \% \mathrm{CI})$ & $\begin{array}{l}\chi^{2} \\
P \text {-value }\end{array}$ & & $\begin{array}{l}\text { Controls } \\
\mathrm{n}=1192(\%)\end{array}$ & $\begin{array}{l}\text { Cases } \\
\mathrm{n}=1240(\%)\end{array}$ & OR $(95 \% \mathrm{CI})$ & $\begin{array}{l}\chi^{2} \\
P \text {-value }\end{array}$ \\
\hline \multicolumn{6}{|c|}{ Genotype frequencies } & \multicolumn{5}{|c|}{ Allele frequencies } \\
\hline \multicolumn{6}{|c|}{ rs523349 in SRD5A2 } & \multirow{4}{*}{$\begin{array}{l}C \\
G\end{array}$} & \multirow{4}{*}{$\begin{array}{l}835(70 \%) \\
357(30 \%)\end{array}$} & \multirow{4}{*}{$\begin{array}{l}845(69 \%) \\
373(31 \%)\end{array}$} & & \multirow{4}{*}{$\begin{array}{l}\text { ref } \\
0.719\end{array}$} \\
\hline$C C$ & $290(49 \%)$ & $291(48 \%)$ & 1.00 & (ref) & ref & & & & & \\
\hline$C G$ & $255(43 \%)$ & $263(43 \%)$ & 1.03 & $(0.81-1.30)$ & 0.820 & & & & 1.00 (ref) & \\
\hline$G G$ & $51 \quad(9 \%)$ & $55 \quad(9 \%)$ & 1.07 & $(0.71-1.63)$ & 0.733 & & & & $1.03(0.87-1.23)$ & \\
\hline \multicolumn{6}{|c|}{ rs6932902 in ESR1 } & \multirow{4}{*}{ G } & \multirow{4}{*}{$\begin{array}{r}1046(88 \%) \\
146(12 \%)\end{array}$} & $373(31 \%)$ & & \multirow{2}{*}{0.719} \\
\hline$G G$ & $459(77 \%)$ & $448(73 \%)$ & 1.00 & (ref) & ref & & & & & \\
\hline$A G$ & $128(21 \%)$ & $153(25 \%)$ & 1.22 & $(0.94-1)$ & 0.139 & & & $1049(85 \%)$ & 1.00 (ref) & ref \\
\hline$A A$ & $9(2 \%)$ & $16 \quad(3 \%)$ & 1.82 & $(0.80-4$ & 0.150 & & & $185(15 \%)$ & $1.26(1.00-1.60)$ & 0.049 \\
\hline \multicolumn{6}{|c|}{ rs2987983 in ESR2 } & \multirow{4}{*}{$\begin{array}{l}A \\
G\end{array}$} & \multirow{4}{*}{$\begin{array}{l}804(67 \%) \\
386(32 \%)\end{array}$} & \multirow{4}{*}{$\begin{array}{l}865(71 \%) \\
357(29 \%)\end{array}$} & & \multirow{4}{*}{$\begin{array}{l}\text { ref } \\
0.087\end{array}$} \\
\hline$A A$ & $265(45 \%)$ & $308(50 \%)$ & 1.00 & (ref) & ref & & & & & \\
\hline$A G$ & $274(46 \%)$ & $249(41 \%)$ & 0.78 & $(0.62-0$ & 0.042 & & & & 1.00 (ref) & \\
\hline$G G$ & $56(9 \%)$ & $54(9 \%)$ & 0.83 & $(0.55-1.25)$ & 0.370 & & & & $0.86(0.72-1.02)$ & \\
\hline \multicolumn{6}{|c|}{ rs11119982 in ATF3 } & \multirow{4}{*}{$\begin{array}{l}C \\
T\end{array}$} & & & & \multirow{4}{*}{$\begin{array}{l}\text { ref } \\
0.036\end{array}$} \\
\hline$C C$ & $162(27 \%)$ & $132(22 \%)$ & 1.00 & (ref) & ref & & & & & \\
\hline$C T$ & $285(48 \%)$ & $310(51 \%)$ & 1.33 & $(1.01-1.77)$ & 0.043 & & $609(51 \%)$ & $574(47 \%)$ & $1.00(\mathrm{ref})$ & \\
\hline$T T$ & $148(25 \%)$ & $170(28 \%)$ & 1.41 & $(1.03-1.94)$ & 0.035 & & $581(49 \%)$ & $650(53 \%)$ & $1.19(1.01-1.39)$ & \\
\hline
\end{tabular}

The first shaded column presents the odds ratios and $95 \%$ confidence intervals comparing the two other genotypes to the most frequent homozygous genotype in controls as well as the statistical significance of the differences in genotype distributions between cases and controls. The second shaded column has the same structure, but for alleles.

when they restricted the analyses to only Swedish cases, the association was still observed, making population stratification in their study unlikely as well. We do not expect spurious results due to the different sources of the DNA used in our study because results were comparable in the stratified analyses. Small sample sizes may result in insufficient power to detect an association and may lead to genotype frequencies that are not representative of the frequencies in the population from which the sample was drawn due to chance. Therefore, we collected a large study sample of approximately 600 cases and 600 controls, providing a power of $82-94 \%$, given an alpha of 0.05 , to detect associations between hypospadias and SNPs with allele frequencies between 0.1 and 0.5 and a dominant genetic effect increasing the risk of disease 1.5-fold (a conservative estimate based on the previous studies shown in Table 3).

Differences in results between our and other studies may also be caused by disease heterogeneity due to differences in the criteria used to select the cases. Indeed, more than $25 \%$ of the cases used in the Chinese and Japanese studies had micropenis $(24,25)$, which were nearly absent in our study population. Furthermore, the study by Thai et al. (23) included a high proportion of familial cases. However, a subanalysis in their publication restricted to sporadic cases only still showed the association (23), suggesting that familiality did not explain the observed association. All three studies mentioned above included more hypospadias cases with a posterior localization of the meatus than we did (23-25). We tried to tackle this inconsistency between the studies by analyzing our data separately for the different categories of hypospadias, but comparable results were found in the different subgroups. In addition, we excluded patients with disorders of sex development or micropenis in an attempt to increase the homogeneity of our sample. This did not change the results either (data not shown). These findings suggest that localization of the meatus and familiality are no adequate explanation for the differences in results.

Because the populations analyzed in the other studies are indeed dissimilar to the Dutch population and some of the populations even differ in ethnicity, a real difference between the populations studied might exist. There may be a difference in the etiology of hypospadias, manifested as other underlying trait loci or their alleles, or a difference in environmental exposures between populations. One can speculate that specific SNPs lead to an increased susceptibility of hypospadias only in the presence of an environmental exposure. Factors suspected to be of relevance in the etiology of hypospadias and potentially differing between populations include maternal age, assisted reproductive techniques, and iron supplementation $(5,32$, $37,38)$. Furthermore, there might be a difference in genetic backgrounds, affecting the associations if these are dependent on interactions with other SNPs that are present in one population but not in another or on linkage disequilibrium with a causal allele. Because the SNPs in ESR1, ESR2, and ATF3 are haplotype-tagging SNPs and haplotype block patterns may differ between populations, these SNPs might be in linkage disequilibrium with the causal SNPs in some populations but not in others. The SNP in SRD 5A2, which causes a valine to leucine (V89L) substitution resulting in an approximately $30 \%$ decrease in enzyme activity $(39,40)$, is likely to be a causal SNP but not in our population.

Our failure to replicate the previous findings in a large, well-powered study should not be taken as evidence that the tested genes do not contribute to disease risk. For the reasons explained above, we cannot exclude the possibility that the SNPs investigated in this study are associated 
TABLE 3. Association analyses for single nucleotide polymorphisms in SRD5A2, ESR1, ESR2 and ATF3 with hypospadias in our study and in previously published studies

\begin{tabular}{|c|c|c|c|c|c|c|c|c|c|}
\hline & $\begin{array}{c}\text { Controls } \\
\text { n } \quad(\%)\end{array}$ & \begin{tabular}{l}
\multicolumn{2}{l}{ Cases } \\
n $\quad(\%)$
\end{tabular} & OR $(95 \% \mathrm{CI})$ & $\begin{array}{l}\chi^{2} \\
P \text {-value }\end{array}$ & & $\begin{array}{r}\text { Controls } \\
\text { n }(\%)\end{array}$ & $\begin{array}{l}\text { Cases } \\
\mathrm{n}(\%)\end{array}$ & OR $(95 \% \mathrm{CI})$ & $\begin{array}{l}\chi^{2} \\
P \text {-value }\end{array}$ \\
\hline \multicolumn{5}{|c|}{ Genotype frequencies } & \multicolumn{5}{|c|}{ Allele frequencies } \\
\hline \multicolumn{10}{|c|}{ rs523349 in SRD5A2 } \\
\hline \multicolumn{5}{|c|}{ Thai et al.(23) (mixed ethnicity) ( $n=158$ cases, 96 controls) } & \multirow{4}{*}{$\begin{array}{l}C \\
G\end{array}$} & \multirow{4}{*}{$\begin{array}{r}136(71 \%) \\
56(29 \%)\end{array}$} & \multirow{4}{*}{$\begin{array}{l}152(48 \%) \\
164(52 \%)\end{array}$} & \multirow{4}{*}{$\begin{array}{l}1.0 \text { (ref) } \\
2.6(1.8-3.8)\end{array}$} & \multirow{4}{*}{$\begin{array}{l}\text { ref } \\
<0.001\end{array}$} \\
\hline$C C$ & $59(62 \%)$ & $44(28 \%)$ & 1.0 (ref) & ref & & & & & \\
\hline$C G$ & $18(19 \%)$ & $64(41 \%)$ & $4.8(2.5-9.2)$ & $<0.001$ & & & & & \\
\hline$G G$ & $19(20 \%)$ & $50(32 \%)$ & $3.5(1.8-6.8)$ & $<0.001$ & & & & & \\
\hline \multicolumn{5}{|c|}{ Wang et al.(24) (Chinese) ( $n=90$ cases, 87 controls) } & \multirow{4}{*}{$\begin{array}{l}C \\
G\end{array}$} & \multirow{4}{*}{$\begin{array}{r}106(61 \%) \\
68(39 \%)\end{array}$} & \multirow{4}{*}{$\begin{array}{l}84(47 \%) \\
96(53 \%)\end{array}$} & & \multirow{4}{*}{$\begin{array}{l}\text { ref } \\
0.007\end{array}$} \\
\hline$C C$ & $31(36 \%)$ & $16(18 \%)$ & 1.0 (ref) & ref & & & & & \\
\hline$C G$ & $44(51 \%)$ & $52(58 \%)$ & $2.3(1.1-4.7)$ & 0.024 & & & & 1.0 (ref) & \\
\hline$G G$ & $12(14 \%)$ & $22(24 \%)$ & $3.6(1.4-9.0)$ & 0.007 & & & & $1.8(1.2-2.7)$ & \\
\hline \multicolumn{5}{|c|}{ Our results ( $n=609$ cases, 596 controls) } & \multirow{4}{*}{$\begin{array}{l}C \\
G\end{array}$} & & \multirow{4}{*}{$\begin{array}{l}845(69 \%) \\
373(31 \%)\end{array}$} & & \multirow{4}{*}{$\begin{array}{l}\text { ref } \\
0.719\end{array}$} \\
\hline$C C$ & $290(49 \%)$ & $291(48 \%)$ & 1.0 (ref) & ref & & & & & \\
\hline$C G$ & $255(43 \%)$ & $263(43 \%)$ & $1.0(0.8-1.3)$ & 0.820 & & $835(70 \%)$ & & $1.0(\mathrm{ref})$ & \\
\hline$G G$ & $51 \quad(9 \%)$ & $55(9 \%)$ & $1.1(0.7-1.6)$ & 0.733 & & $357(30 \%)$ & & $1.0(0.9-1.2)$ & \\
\hline \multicolumn{10}{|c|}{ rs6932902 in ESR1 } \\
\hline \multicolumn{5}{|c|}{ Watanabe et al. (25) (Japanese) ( $n=43$ cases, 135 controls) } & \multirow{6}{*}{$\begin{array}{l}G \\
A\end{array}$} & \multirow{4}{*}{$\begin{array}{r}211(78 \%) \\
59(22 \%)\end{array}$} & \multirow{4}{*}{$\begin{array}{l}50(58 \%) \\
36(42 \%)\end{array}$} & & \\
\hline$G G$ & $80(59 \%)$ & $18(42 \%)$ & 1.0 (ref) & ref & & & & & \\
\hline$A G$ & $51(38 \%)$ & $14(33 \%)$ & $1.2(0.6-2.7)$ & 0.619 & & & & $1.0(\mathrm{ref})$ & \\
\hline$A A$ & $4 \quad(3 \%)$ & $11(26 \%)$ & $12.2(3.1-57.0)^{\mathrm{a}}$ & $<0.001$ & & & & $2.6(1.5-4.3)$ & $<0.001$ \\
\hline Our re & ults $(n=617 \mathrm{cc}$ & ses, 596 cont & & & & & & & \\
\hline$G G$ & $459(77 \%)$ & $448(73 \%)$ & 1.0 (ref) & ref & & & & & \\
\hline$A G$ & $128(22 \%)$ & $153(25 \%)$ & $1.2(0.9-1.6)$ & 0.139 & $G$ & $1046(88 \%)$ & $1049(85 \%)$ & $1.0(\mathrm{ref})$ & ref \\
\hline$A A$ & $9 \quad(2 \%)$ & $16 \quad(3 \%)$ & $1.8(0.8-4.2)$ & 0.150 & $A$ & $146(12 \%)$ & $185(15 \%)$ & $1.3(1.0-1.6)$ & 0.049 \\
\hline$r s 2987$ & 83 in ESR2 & & & & & & & & \\
\hline Beleza & Meireles et al. & (27) (Swedis) & $(n=348$ cases, 3 & 7 controls) & & & & & \\
\hline$A A$ & $182(48 \%)$ & $142(41 \%)$ & 1.0 (ref) & ref & & & & & \\
\hline$A G$ & $162(43 \%)$ & $151(43 \%)$ & $1.2(0.9-1.6)$ & 0.264 & $A$ & $526(70 \%)$ & $435(63 \%)$ & 1.0 (ref) & ref \\
\hline$G G$ & $33 \quad(9 \%)$ & $55(16 \%)$ & $2.1(1.3-3.5)$ & 0.002 & $G$ & $228(30 \%)$ & $261(38 \%)$ & $1.4(1.1-1.7)$ & 0.004 \\
\hline Our re & ults $(n=611 \mathrm{cc}$ & ses, 595 cont & & & & & & & \\
\hline$A A$ & $265(45 \%)$ & $308(50 \%)$ & 1.0 (ref) & ref & & & & & \\
\hline$A G$ & $274(46 \%)$ & $249(41 \%)$ & $0.8(0.6-1.0)$ & 0.042 & $A$ & $804(68 \%)$ & $865(71 \%)$ & 1.0 (ref) & ref \\
\hline$G G$ & $56 \quad(9 \%)$ & $54 \quad(9 \%)$ & $0.8(0.6-1.3)$ & 0.370 & $G$ & $386(32 \%)$ & $357(29 \%)$ & $0.9(0.7-1.0)$ & 0.087 \\
\hline$r s 1111$ & 982 in $A T F 3$ & & & & & & & & \\
\hline Beleza. & Meireles et al. & (29) (Swedisl & ) $(n=330$ cases, 3 & 4 controls) & & & & & \\
\hline$C C$ & $60(16 \%)$ & $82(25 \%)$ & 1.0 (ref) & ref & & & & & \\
\hline$C T$ & $168(45 \%)$ & $160(48 \%)$ & $0.7(0.5-1.0)$ & 0.074 & C & $288(39 \%)$ & $324(49 \%)$ & 1.0 (ref) & ref \\
\hline$T T$ & $146(39 \%)$ & $88(27 \%)$ & $0.4(0.3-0.7)$ & $<0.001$ & $T$ & $460(61 \%)$ & $336(51 \%)$ & $0.6(0.5-0.8)$ & $<0.001$ \\
\hline Our re & ults $(n=612 \mathrm{cc}$ & ses, 595 cont & ols) & & & & & & \\
\hline$C C$ & $162(27 \%)$ & $132(22 \%)$ & 1.0 (ref) & ref & & & & & \\
\hline$C T$ & $285(48 \%)$ & $310(51 \%)$ & $1.3(1.0-1.8)$ & 0.043 & C & $609(51 \%)$ & 574 (47) & 1.0 (ref) & ref \\
\hline$T T$ & $148(25 \%)$ & $170(28 \%)$ & $1.4(1.0-1.9)$ & 0.035 & $T$ & $581(49 \%)$ & $650(53 \%)$ & $1.2(1.0-1.4)$ & 0.036 \\
\hline
\end{tabular}

The left half of the table presents genotype data and the right half allelic data. For each SNP, both our results and those from previously published studies are displayed. The first three columns of this table present the genotype distribution of the four SNPs investigated among hypospadias cases and controls. The shaded column presents the odds ratios and $95 \%$ confidence intervals comparing the two other genotypes to the most frequent homozygous genotype in controls as well as the statistical significance of the differences in genotype distributions between cases and controls. The right half of the table has the same structure, but shows allele frequencies.

aExact 95\% Cl calculated using the Fisher exact method.

with hypospadias in some populations. In addition, one should keep in mind that we examined only one SNP per gene. Other SNPs, SNP-haplotypes, or other types of polymorphisms, such as variable number tandem repeats, e.g. those reported in ESR2 (28) and potentially also copy number polymorphisms, may be of relevance for hypospadias risk as well.

Our study once again confirms the importance of replication studies for the validation of the results of genetic association approaches. These studies can provide information about the generalizability of the findings and contribute to the determination of realistic estimates of effect sizes. In addition, in the specific case of hypospadias, in which clear evidence regarding the molecular pathways leading to disease is lacking, methods such as genome-wide association studies may be called for rather than candidate gene approaches to generate hypotheses regarding the pathways and genes involved in the etiology of hypospadias.

\section{Acknowledgments}

We are grateful to all patients, their parents, and controls for their participation in the study and to Karen Kwak, Jacqueline Knoll, Robert de Gier, Barbara Kortmann, Astrid Paauwen, Kwan Kho, Jacques Driessen, the other anesthesiologists of operation room 18, and all others involved in the collection of the case samples. The control samples were derived from the Nijmegen Biomedical Study. Principal investigators of the Nijmegen Biomedical Study are L.A.L.M.K., M. den Heijer, A. L. M. Verbeek, D. W. Swinkels, and B.F. S.H.H.M.V. and L.A.L.M.K. participated as representatives of the Nijmegen Biomedical Study.

Address all correspondence and requests for reprints to: Barbara Franke, Ph.D., Department of Human Genetics, 855, Radboud University Nijmegen Medical Centre, P.O. Box 9101, 6500 HB Nijmegen, The Netherlands. E-mail: B.Franke@antrg.umcn.nl. 
This work was performed within a PhD project supported by the Radboud University Nijmegen Medical Centre.

Disclosure Summary: The authors have nothing to disclose.

\section{References}

1. International Clearinghouse for Birth Defects Surveillance and Research 2009 Annual report 2008, with data for 2006. Available at: http://www.icbdsr.org/page.asp? $\mathrm{p}=\% 2010065 \& \mathrm{l}=1$. Accessed December 3, 2009

2. Yamada G, Satoh Y, Baskin LS, Cunha GR 2003 Cellular and molecular mechanisms of development of the external genitalia. Differentiation 71:445-460

3. Crescioli C, Maggi M, Vannelli GB, Ferruzzi P, Granchi S, Mancina R, Muratori M, Forti G, Serio M, Luconi M 2003 Expression of functional estrogen receptors in human fetal male external genitalia. J Clin Endocrinol Metab 88:1815-1824

4. Kim KS, Torres Jr CR, Yucel S, Raimondo K, Cunha GR, Baskin LS 2004 Induction of hypospadias in a murine model by maternal exposure to synthetic estrogens. Environ Res 94:267-275

5. North K, Golding J 2000 A maternal vegetarian diet in pregnancy is associated with hypospadias. BJU Int 85:107-113

6. Liu B, Wang Z, Lin G, Agras K, Ebbers M, Willingham E, Baskin LS 2005 Activating transcription factor 3 is up-regulated in patients with hypospadias. Pediatr Res 58:1280-1283

7. Wang Z, Liu BC, Lin GT, Lin CS, Lue TF, Willingham E, Baskin LS 2007 Up-regulation of estrogen responsive genes in hypospadias: microarray analysis. J Urol 177:1939-1946

8. Fredell L, Kockum I, Hansson E, Holmner S, Lundquist L, Läckgren G, Pedersen J, Stenberg A, Westbacke G, Nordenskjöld A 2002 Heredity of hypospadias and the significance of low birth weight. J Urol 167:1423-1427

9. Schnack TH, Zdravkovic S, Myrup C, Westergaard T, Christensen K, Wohlfahrt J, Melbye M 2008 Familial aggregation of hypospadias: a cohort study. Am J Epidemiol 167:251-256

10. Alléra A, Herbst MA, Griffin JE, Wilson JD, Schweikert HU, McPhaul MJ 1995 Mutations of the androgen receptor coding sequence are infrequent in patients with isolated hypospadias. J Clin Endocrinol Metab 80:2697-2699

11. Hiort O, Klauber G, Cendron M, Sinnecker GH, Keim L, Schwinger E, Wolfe HJ, Yandell DW 1994 Molecular characterization of the androgen receptor gene in boys with hypospadias. Eur J Pediatr 153:317-321

12. Nordenskjöld A, Friedman E, Tapper-Persson M, Söderhäll C, Leviav A, Svensson J, Anvret M 1999 Screening for mutations in candidate genes for hypospadias. Urol Res 27:49-55

13. Sutherland RW, Wiener JS, Hicks JP, Marcelli M, Gonzales Jr ET, Roth DR, Lamb DJ 1996 Androgen receptor gene mutations are rarely associated with isolated penile hypospadias. J Urol 156:828-831

14. Silver RI, Russell DW $19995 \alpha$-reductase type 2 mutations are present in some boys with isolated hypospadias. J Urol 162:1142-1145

15. Codner E, Okuma C, Iñiguez G, Boric MA, Avila A, Johnson MC, Cassorla FG 2004 Molecular study of the $3 \beta$-hydroxysteroid dehydrogenase gene type II in patients with hypospadias. J Clin Endocrinol Metab 89:957-964

16. Fukami M, Wada Y, Miyabayashi K, Nishino I, Hasegawa T, Nordenskjöld A, Camerino G, Kretz C, Buj-Bello A, Laporte J, Yamada G, Morohashi K, Ogata T 2006 CXorf6 is a causative gene for hypospadias. Nat Genet 38:1369-1371

17. Chen T, Li Q, Xu J, Ding K, Wang Y, Wang W, Li S, Shen Y 2007 Mutation screening of BMP4, BMP7, HOXA4 and HOXB6 genes in Chinese patients with hypospadias. Eur J Hum Genet 15:23-28

18. Beleza-Meireles A, Lundberg F, Lagerstedt K, Zhou X, Omrani D, Frisén L, Nordenskjöld A 2007 FGFR2, FGF8, FGF10 and BMP7 as candidate genes for hypospadias. Eur J Hum Genet 15:405-410

19. Fredell L, Iselius L, Collins A, Hansson E, Holmner S, Lundquist L, Läckgren G, Pedersen J, Stenberg A, Westbacke G, Nordenskjöld A 2002 Complex segregation analysis of hypospadias. Hum Genet 111:231-234
20. Peng B, Kimmel M 2007 Simulations provide support for the common disease-common variant hypothesis. Genetics 175:763-776

21. Radpour R, Rezaee M, Tavasoly A, Solati S, Saleki A 2007 Association of long polyglycine tracts (GGN repeats) in exon 1 of the androgen receptor gene with cryptorchidism and penile hypospadias in Iranian patients. J Androl 28:164-169

22. Aschim EL, Nordenskjöld A, Giwercman A, Lundin KB, Ruhayel Y, Haugen TB, Grotmol T, Giwercman YL 2004 Linkage between cryptorchidism, hypospadias, and GGN repeat length in the androgen receptor gene. J Clin Endocrinol Metab 89:5105-5109

23. Thai HTT, Kalbasi M, Lagerstedt K, Frisén L, Kockum I, Nordenskjöld A 2005 The valine allele of the V89L polymorphism in the 5- $\alpha$ reductase gene confers a reduced risk for hypospadias. J Clin Endocrinol Metab 90:6695-6698

24. Wang Y, Li Q, Xu J, Liu Q, Wang W, Lin Y, Ma F, Chen T, Li S, Shen Y 2004 Mutation analysis of five candidate genes in Chinese patients with hypospadias. Eur J Hum Genet 12:706-712

25. Watanabe M, Yoshida R, Ueoka K, Aoki K, Sasagawa I, Hasegawa T, Sueoka K, Kamatani N, Yoshimura Y, Ogata T 2007 Haplotype analysis of the estrogen receptor 1 gene in male genital and reproductive abnormalities. Hum Reprod 22:1279-1284

26. Ban S, Sata F, Kurahashi N, Kasai S, Moriya K, Kakizaki H, Nonomura K, Kishi R 2008 Genetic polymorphisms of ESR1 and ESR2 that may influence estrogen activity and the risk of hypospadias. Hum Reprod 23:1466-1471

27. Beleza-Meireles A, Kockum I, Lundberg F, Söderhäll C, Nordenskiöld A 2007 Risk factors for hypospadias in the estrogen receptor 2 gene. J Clin Endocrinol Metab 92:3712-3718

28. Beleza-Meireles A, Omrani D, Kockum I, Frisén L, Lagerstedt K, Nordenskjöld A 2006 Polymorphisms of estrogen receptor $\beta$ gene are associated with hypospadias. J Endocrinol Invest 28:5-10

29. Beleza-Meireles A, Töhönen V, Söderhäll C, Schwentner C, Radmayr C, Kockum I, Nordenskjöld A 2008 Activating transcription factor 3: a hormone responsive gene in the etiology of hypospadias. Eur J Endocrinol 158:729-739

30. Ioannidis JP, Ntzani EE, Trikalinos TA, Contopoulos-Ioannidis DG 2001 Replication validity of genetic association studies. Nat Genet 29:306-309

31. Colhoun HM, McKeigue PM, Davey Smith G 2003 Problems of reporting genetic associations with complex outcomes. Lancet 361:865-872

32. Brouwers MM, Feitz WFJ, Roelofs LAJ, Kiemeney LALM, de Gier RPE, Roeleveld N 2007 Risk factors for hypospadias. Eur J Pediatr 166:671-678

33. Brouwers MM, van der Zanden LFM, de Gier RPE, Barten EJ, Zielhuis GA, Feitz WFJ, Roeleveld N 2009 Hypospadias: risk factor patterns and different phenotypes. BJU Int 105:254-262

34. Hoogendoorn EH, Hermus AR, de Vegt F, Ross HA, Verbeek ALM, Kiemeney LALM, Swinkels DW, Sweep FCGJ, den Heijer M 2006 Thyroid function and prevalence of anti-thyroperoxidase antibodies in a population with borderline sufficient iodine intake: influences of age and sex. Clin Chem 52:104-111

35. Hirschhorn JN, Lohmueller K, Byrne E, Hirschhorn K 2002 A comprehensive review of genetic association studies. Genet Med 4:45-61

36. Sillanpää MJ, Auranen K 2004 Replication in genetic studies of complex traits. Ann Hum Genet 68:646-657

37. Källén B, Finnström O, Nygren KG, Olausson PO 2005 In vitro fertilization (IVF) in Sweden: risk for congenital malformations after different IVF methods. Birth Defects Res A Clin Mol Teratol 73:162-169

38. Porter MP, Faizan MK, Grady RW, Mueller BA 2005 Hypospadias in Washington State: maternal risk factors and prevalence trends. Pediatrics 115:e495-e499

39. Makridakis N, Ross RK, Pike MC, Chang L, Stanczyk FZ, Kolonel LN, Shi CY, Yu MC, Henderson BE, Reichardt JKV 1997 A prevalent missense substitution that modulates activity of prostatic steroid $5 \alpha$-reductase. Cancer Res 57:1020-1022

40. Makridakis NM, di Salle E, Reichardt JKV 2000 Biochemical and pharmacogenetic dissection of human steroid $5 \alpha$-reductase type II. Pharmacogenetics 10:407-413 